\title{
A methodology to simulate annual blind use in large open plan offices
}

\author{
Kieu Pham ${ }^{1}$, Ayman Wagdy ${ }^{1}$, Gillian Isoardi ${ }^{2}$, Alicia Allan ${ }^{1}$, Veronica Garcia Hansen ${ }^{1}$ \\ ${ }^{1}$ Queensland University of Technology, Brisbane, Australia \\ ${ }^{2}$ Light Naturally, Brisbane, Australia
}

\begin{abstract}
Occupant behaviour (OB) models relating to daylighting and blind use have been developed for cellular office configurations. However, this is not the case for large open plan offices that represent different spatial, daylighting and occupancy characteristics. This paper presents a methodology to simulate annual blind use based on the daylight availability for large open plan offices. A novel multi-directional illuminance grid was used to simulate annual blind use; to account for multiple view-points and occupants. The results found that this method can be used to predict annual blind use in large open plan offices to improve building performance simulations and occupancy models.
\end{abstract}

\section{Introduction}

Optimising natural light to support visual comfort for building occupants whilst reducing energy consumption is a pertinent goal in green building design. However, occupants play a highly influential role on building performance and energy use (Asadi, Mahyuddin, \& Shafigh, 2017; Fabi, Andersen, Corgnati, \& Olesen, 2012; Gunay, O'Brien, \& Beausoleil-Morrison, 2013; Haldi \& Robinson, 2011; Jia \& Srinivasan, 2015). In the case of visual comfort, occupants can make adaptive changes to electrical lights (switch on/off), blinds (occlusion) and/or localised interventions (i.e. cardboard to block view of glare or bright sources of light) to restore comfort levels (Roche, Dewey, \& Littlefair, 2000). However, these adaptive actions can undermine electrical efficiency strategies (Gunay et al., 2013). Thus, occupant behaviour models $(\mathrm{OB})$ have been developed to better account for behaviour leading to adaptive changes to reduce this uncertainty. The goal for OB models is to predict behaviour by realistically simulating user interactions and/or presence. Accurate models allow for realistic simulations of building system use to determine the most effective system strategies.

Current OB models relating to visual comfort and blind use have only been developed for cellular office configurations. These offices typically contain single or shared occupancy and feature one window opening and blind shade. One of the earliest OB models was developed by Newsham (1994) called Lightswitch. This model was based on predicting blind use and light switch on/off events to improve thermal comfort. A south facing cellular room $(4.5 \times 7.5 \times 3 \mathrm{~m})$ was developed using
FENESTRA. If the solar intensity of $233 \mathrm{~W} / \mathrm{m}^{2}$ reached an occupant (based on the sunlight patch depth), the probability for blind shade operation would be $20 \%$. This threshold was based on a field study conducted by Inoue, Kawase, Ibamoto, Takakusa, and Matsuo (1988) who found that the depth of sunlight penetration in a room was proportional to the percentage of blinds closed in a room. Similarly, Reinhart (2004) developed a model called Lightswitch-2002 to predict manual blinds and electrical light switch on/off events for cellular offices using a stochastic approach. The control algorithm for blind use prediction was based on solar irradiance from previous field studies. If $50 \mathrm{~W} / \mathrm{m}^{2}$ reached the workstation, blinds would be fully lowered and re-opened every morning the following day upon occupants' arrival to work.

The issue is that these models may not be suitable to predict blind shade use in large open plan offices. Unlike cellular offices, occupants in open plan offices have exposure to both natural and electrical light sources from multiple direction and orientations. Modern open plan offices are designed with undivided walls to accommodate the greater portion of the office population. Predominate features such as floor to ceiling height glazing/windows along the building perimeter are maximised to optimise the benefits of natural light (Green Building Council of Australia, 2008; Leadership in Energy and Envrionmental Design, 2013). Generally, to provide sufficient electrical lighting in offices, 320 lux (maintained illuminance) is recommended for screenbased activities for either the horizontal or vertical workplane. For daylighting control strategies, blind shades are recommended to prevent visual discomfort or glare (Australian Standards, 2006, 2008). In the case of green buildings, blind shades are required to achieve a visual light transmittance of $\leq 10 \%$ (Green Building Council of Australia, 2017). However, in large open plan offices that have a window to wall ratio (WWR) as great as $90 \%$, the vertical illuminance would be a considerable factor for blind use modelling; particularly when work activities are conducted on vertical display terminals (VDT). Thus, existing thresholds used to predict blind shade use may not be optimal if the directionality of the occupants' dominant facing position is on the vertical plane. These considerations would need to be accounted for in OB models particularly when there are different occupant workstation locations, multiple view orientations and daylight sources. This has yet to be explored. Such an unaccounted difference spatially and characteristically 
would make blind use simulations inaccurate (Hoes, Hensen, Loomans, de Vries, \& Bourgeois, 2009). However, one challenge is providing a way to simulate blind use that would consider the aforementioned factors. To this end, the aim of this study was to propose a simulation methodology for annual blind use for large open plan offices; using a novel approach to simulate both the horizontal and vertical illuminance. The simulation methodology also aimed to consider the practical issues of capturing illuminance measurements in a real office setting populated by building occupants to reflect real world conditions.

\section{Simulation methodology}

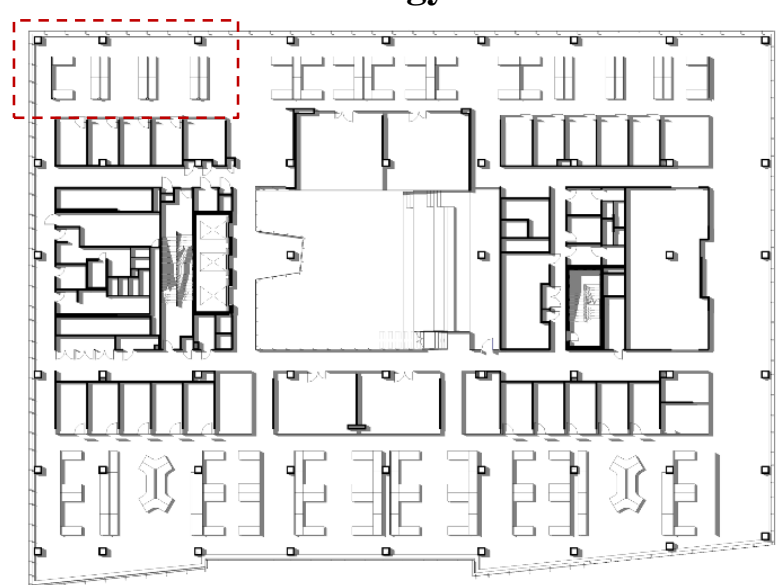

(a)

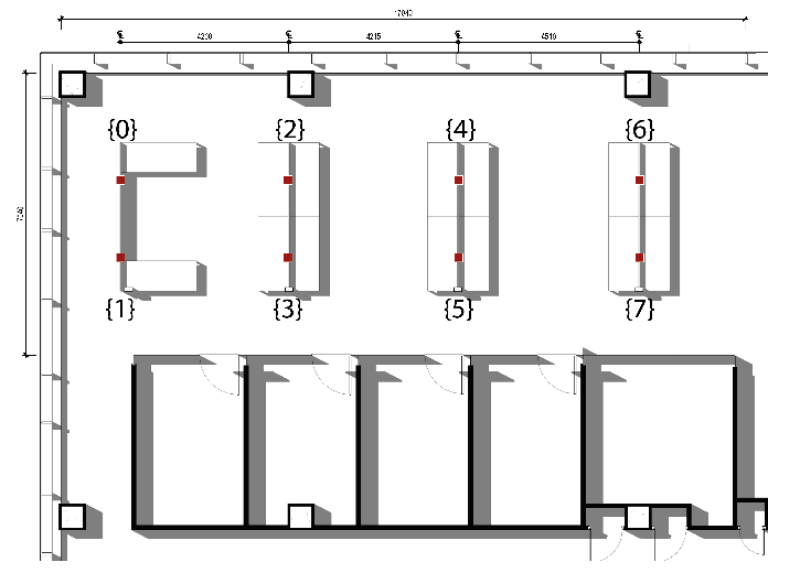

(b)

Figure 1. (a) Case study of a typical large open plan office in Brisbane, Australia. (b) North-west portion of the office was examined using a multi-directional illuminance grid indicated in red.

A large open plan office located on the seventh floor in a subtropical climate in Brisbane, Australia (27²8'41.921" $\mathrm{N}, 153^{\circ} 1^{\prime} 45.632^{\prime}$ E, atl.11m) was selected as a case study.

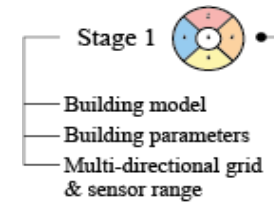

The building was modelled with no neighbouring buildings. For testing the methodology, only a section of the North-West portion of the office was examined (approx. $15.4 \mathrm{~m} \times 7.2 \mathrm{~m} \times 3 \mathrm{~m}$ ) (refer to Figure 1a). Although a portion of the office was investigated, the method can be extended to simulate an entire floor. The office featured daylight penetration from floor to ceiling height glazing panels (non-operable windows) and solar blind shades (Venetian with no slats). A total of eight workstations separated by shared privacy screens (height $1.13 \mathrm{~m}$ ) were examined (see Figure 1b). The methodology adopted a non-linear algorithmic approach using Grasshopper in Rhinoceros (Rutten, 2014). This approach was selected for its parametric ability to create parameters that can be adjusted and applied over other projects (Wagdy, 2013; Wagdy \& Fathy, 2016).

Further, the methodology was developed to mimic the sensor points of a real datalogger currently deployed in field studies (see Figure 3). These dataloggers were built to capture illuminance in five directions (one horizontal illuminance sensor on the upper cube surface, and 4 vertical illuminance sensors) simultaneously in large open plan offices. This is to determine illuminance thresholds to predict blind opening percentages based on occupant locations. Hence, the proposed methodology was aimed to provide a framework to simulate illuminance values extrapolated from practical and realistic scenarios. In this study a total of 40 sensor points were simulated. The algorithm was developed across three stages (see Figure 2 ). In stage 1, a novel multi-directional illuminance grid was created to simulate the daylight availability from horizontal and vertical sensor points. Stage 2 involved applying a sorting and grouping logic to both blind shades and sensor points. This was to address the issue of deciding which blind shade(s) and sensor point(s) would be triggered. Stage 2 defined illuminance thresholds to trigger blind shade opening percentages; to create a series of annual blind shade schedules. To compare results, Lightswitch-2002 by Reinhart (2004) was used to produce the same blind schedule. The following sections further describe the simulation methodology in detail.

\section{Stage 1: multi-directional illuminance grid}

To simulate annual blind use, a multi-directional illuminance (lux) grid was first developed (see Figure 4). First, parameter points were arbitrarily defined to construct the points and to define the location of each sensor grid. A total of eight grids were placed on top of the privacy screens separating occupant workstations (mounting height $1.13 \mathrm{~m}$ ). This location was considered as the most realistic, consistent and practical position in realworld conditions.

Figure 2. Simulation methodology workflow in three stages 
Five vector rays were constructed for each grid to simulate five sensors (horizontal and vertical planes). Each vector ray was assigned with an identity number $(0$, $1,2,3,4$, etc.,) using the point parameter function; totalling up to forty sensor points. To determine which blind shade was controlled by which sensor point, a $90^{\circ}$ geometrical cone was projected from each sensor, to intersect with the nearest glazing panel. This defined the sensors' control range, which was set to $5 \mathrm{~m}$ for the purposes of this study.

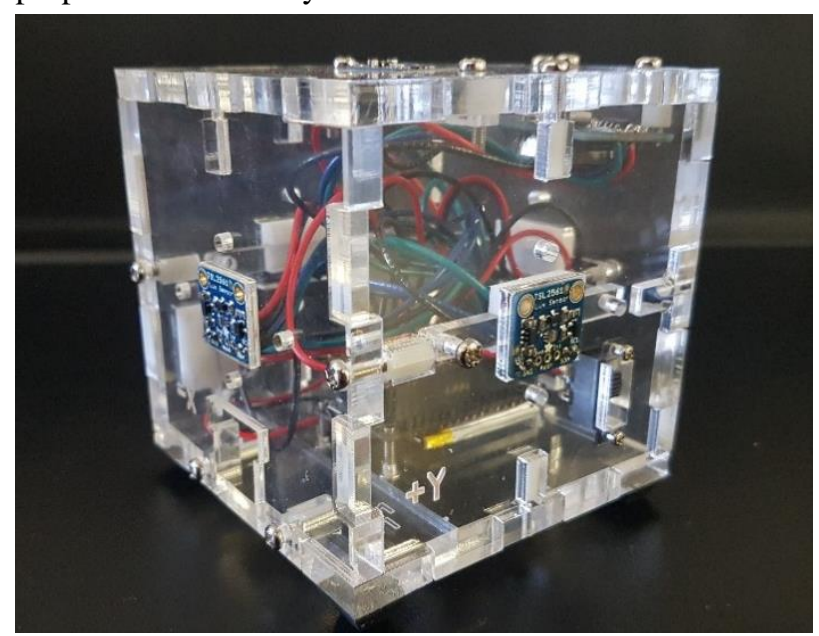

(a)

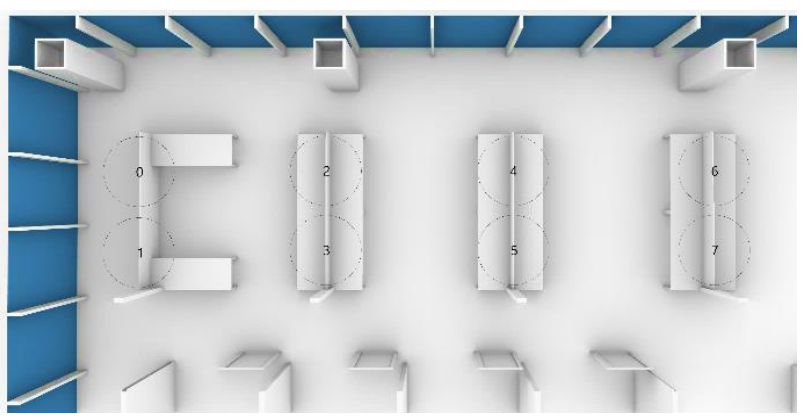

(b)

Figure 3. (a) Dataloggers used to capture empirical data in large open plan office (currently used in field studies). (b) Multi-point illuminance grid based on occupant workstation locations to mimic dataloggers.

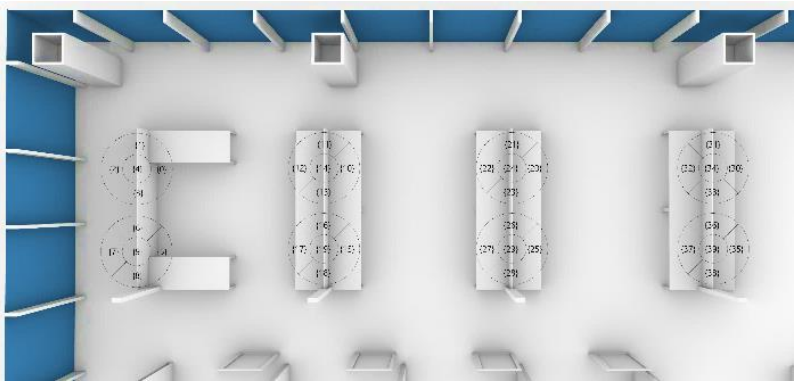

Figure 4. Multi-point illuminance grid simulating five sensor points: four vertical points and 1 horizontal.

\section{Stage 2: sorting and grouping logic}

An annual daylight simulation was initialised to calculate the hourly mean illuminance at each sensor point. This was simulated using an existing local weather data file and parameters described in Table 1. Radiance parameters used were: -aa .1 -ab 7 -ad 4096 -ar 512 -as 1024 -dr 2 ds .2 -lr 12 -lw .001 -dj 0 -lr 6 -sj 1 -st 0.15. The purpose of this step was to calculate the daylight availability for all forty sensor points without blind shades; to apply illuminance thresholds to trigger blind opening percentages for stage 3. A sorting and grouping logic were applied to determine the most likely sensor to control the blind shade(s). Identifying who would control this in a cellular office would be straight forward. However, this methodology would need to account for multiple occupants and to assume that they all share all blind shades. This was reflected in the overlap in the sensors' control range; where multiple sensor points control (intersect) the same blind shades (see Figure 5). Therefore, the calculated mean illuminance for each sensor point was sorted in multiple lists based on the order of performance (highest to lowest mean annual illuminance). The sensor(s) that would trigger the blind shade was therefore based on the sensor(s) that would read the highest illuminance value. A selection criterion was then reversed so that the glazing panels were the selector rather than the sensor points; to sort through the highest performing sensor(s) to trigger blind occlusion.

Table 1. Building and material parameters

\begin{tabular}{|c|c|c|}
\hline \multicolumn{3}{|c|}{ Space parameters } \\
\hline Floor level & \multicolumn{2}{|l|}{$7^{\text {th }}$ floor $(+22.00 \mathrm{~m})$} \\
\hline Gross floor area & \multicolumn{2}{|l|}{$2712.1 \mathrm{~m}^{2}$} \\
\hline $\begin{array}{l}\text { Space area } \\
\text { (studied) }\end{array}$ & $118.1 \mathrm{~m}^{2}$ & $\begin{array}{l}3 \mathrm{~m} \times 16.8 \mathrm{~m} \times \\
7 \mathrm{~m}\end{array}$ \\
\hline \multicolumn{3}{|c|}{ Internal surface materials } \\
\hline Walls & Reflectance & $50 \%$ \\
\hline Ceiling & Reflectance & $80 \%$ \\
\hline Floor & Reflectance & $20 \%$ \\
\hline Furniture & Reflectance & $50 \%$ \\
\hline \multicolumn{3}{|c|}{ Window parameters } \\
\hline WWR & & $90 \%$ \\
\hline Glazing & Transmittance & $80 \%$ \\
\hline Window frame & Reflectance & Metal diffuse \\
\hline \multicolumn{3}{|c|}{ Shading parameters } \\
\hline Blind Type & Manual roller blinds & \\
\hline Blind Material & Transmittance & $4 \%$ \\
\hline \multicolumn{3}{|c|}{ Multi-point illuminance grid } \\
\hline Control range & $5 \mathrm{~m}$ & \\
\hline
\end{tabular}

\section{Stage 3: thresholds and blind scheduling}

To date, there are no agreed thresholds nor metric to define daylight tolerance levels that would trigger occupants to change blind shade settings. Previous studies that have investigated this, have reported different results. As mentioned earlier, Newsham (1994) used the solar intensity of $233 \mathrm{~W} / \mathrm{m}^{2}$ as the predictor variable whereas Reinhart (2004) found $50 \mathrm{~W} / \mathrm{m}^{2}$. Conversely, Lindelöf and Morel (2008) adopted 800 to 1200 lux on the horizontal work-plane to estimate visual discomfort in small offices for both blinds and lighting controls in their probability model, which was consistent with a probability model developed by Haldi and Robinson (2010). These findings were not applied in this study for the illuminance thresholds; since this study assumed that the vertical illuminance would also be a significant predictor variable. This was to account for the vertical viewing position and directionality of the occupants. 


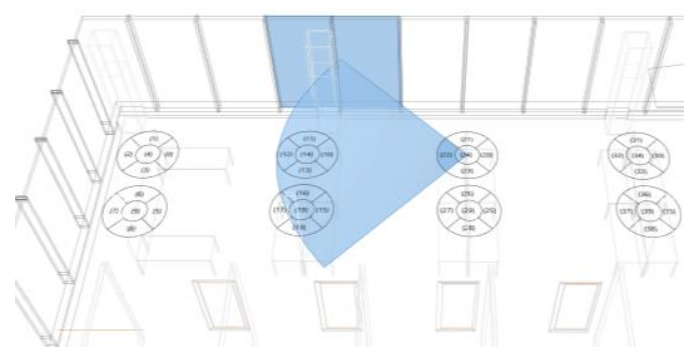

(a)

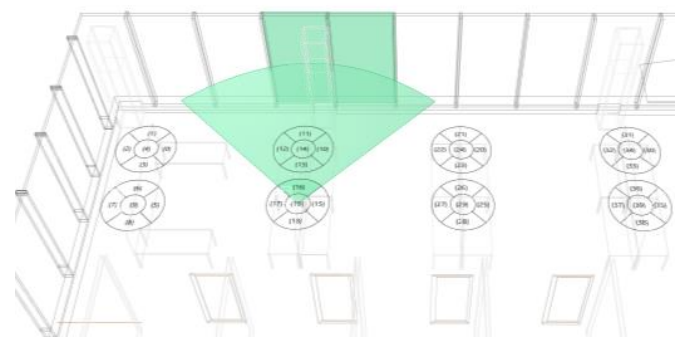

(b)

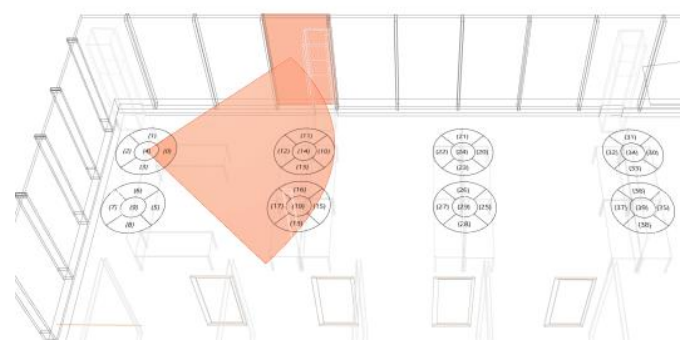

(c)

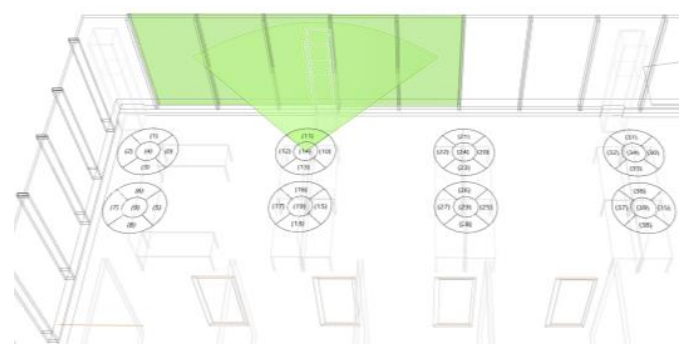

(d)

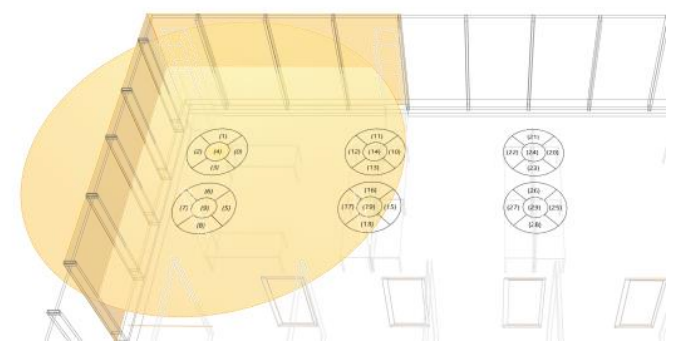

(e)

Figure 5. Example of sensor points selecting the same glazing panels. $(a-d)$ vertical illuminance sensor points and (e) horizontal illuminance from multi-illuminance grid 1. Sorting and grouping logic applied to select sensor to control blind shade.
In this study, the illuminance thresholds were arbitrary to complete the simulation workflow.

However, these parameters can be easily adjusted based on new evidence as derived from ongoing field studies. The illuminance thresholds were applied to predict the blind opening percentage for each blind shade to produce an annual blind shade schedule. This schedule describes the blind shade status as either 0 (fully opened), $0.25,0.5$, 0.75 or 1

(fully closed) at an hourly interval. Blind shade triggering events were set in four different states (for both horizontal and vertical sensor points) that was passed through custom logical gates in Grasshopper:

- 0-200 lux triggers $100 \%$ fully opened

- 200-600 lux triggers 75\% opened

- 600-1200 lux triggers 50\% opened

- 1200-1800 lux triggers $25 \%$ opened

- >1800 lux triggers $0 \%$ opened

The final daylight simulation was performed using the same parameters in Table 1. The results were discussed in detail below.

\section{Results and discussion}

A methodology to simulate annual blind use for large open plan offices was presented, with the goal to provide a framework that can account for the practical implications of extrapolating real-world data. The results show that using a multi-directional illuminance grid to estimate the daylight availability at multiple workstation locations can provide more detailed information about blind use patterns for multiple occupants. This method accounted for vertical illuminances exceeding >1800 lux that would otherwise not be detected with existing models (see Figure 6). Previous studies that have focused on blind shade prediction in cellular offices, typically feature only one window and considered either the horizontal illuminance or solar irradiance as the predictor variable. However, for large open plan offices that have a WWR as great as $90 \%$, multiple view-points to multiple glazing panels (or windows) should be a considered variable to predict blind shade use. This is particularly so if the main work activities are conducted on VDT screens. In comparison to cellular offices, simulating blind shade use is much more complex in large open plan offices that are undivided by internal walls. It would require determining which occupant would be most likely to operate the blind shade(s) and deciding which blind would be occluded. In this case, empirical data would be necessary to further explore this issue.

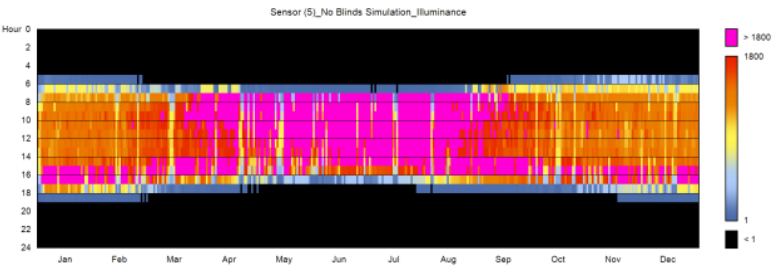

Figure 6. Example of annual illuminance for one vertical sensor point exceeding $>1800$. 
The proposed methodology was compared with Lightswitch-2002. DIVA in Grasshopper was used to simulate an annual blind shade schedule using the same parameters in Table 1. Two annual blind shade schedules were produced from each approach by simulating only one blind shade. Schedules were simulated based on the annual mean illuminance (without blind shades) from Figure $7 \mathrm{a}$.

To make the comparison, the illuminance thresholds were set to only two states: <600 lux (fully opened) and $>600$ lux (fully closed). This was because DIVA was only able to define blind states based on integers $(0=$ fully closed, $1=$ fully opened) and not floating values (i.e. 0.25 ).

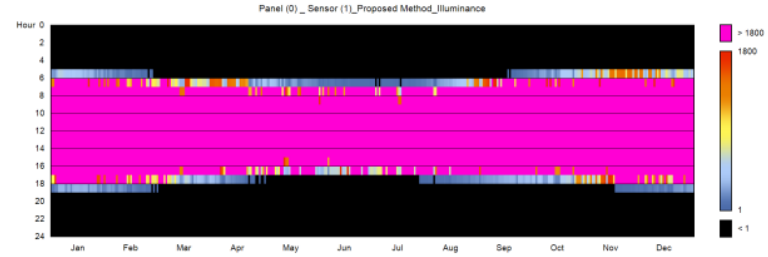

(a)

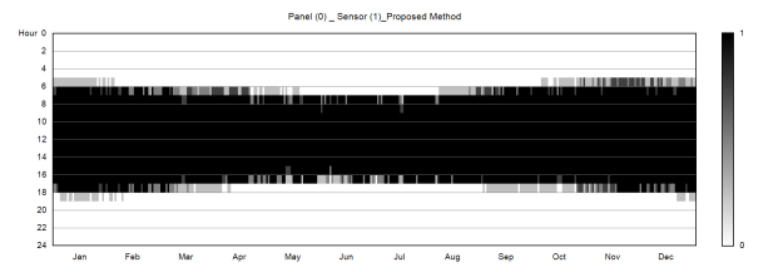

(b)

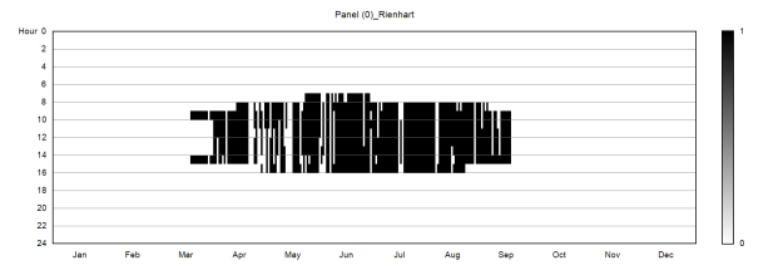

(c)

Figure 7. Simulating one sensor point and blind shade to compare annual blind shade schedule with Lightswitch-2002.

(a) Initial simulation to obtain annual daylight availability (without blind shades). (b) Annual blind shade results using the proposed methodology (vertical illuminance). (c) Annual blind shade results using Lightswitch-2002 (solar irradiance).

The results showed that the proposed methodology predicted annual blind shade use more frequently throughout the day across the entire year as shown in Figure $7 \mathrm{~b}$ (black $=100 \%$ closed and white $=0 \%$ opened). On the other hand, Lightswitch-2002 predicted blind shade use only between May and September as shown in Figure 7c. The difference was due to the unit of measurement, where Lightswitch-2002 predicted blind shade use based on solar irradiance $\left(50 \mathrm{~W} / \mathrm{m}^{2}\right)$; detecting only the most critical times of the year in which the sun would be at its lowest angle. On the other hand, the proposed methodology was able to detect additional brightness (i.e. reflectivity, diffused light etc.) that would influence blind shade use.

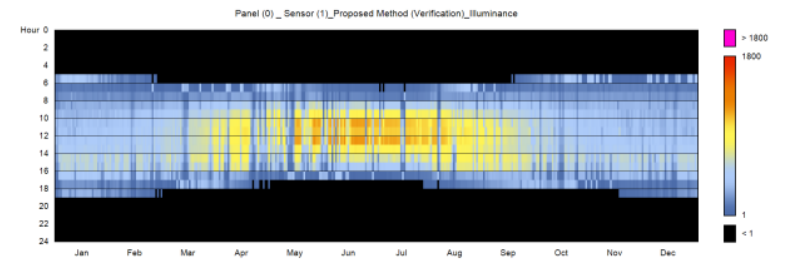

(a)

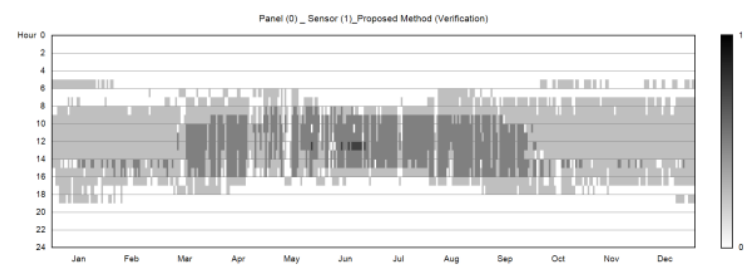

(b)

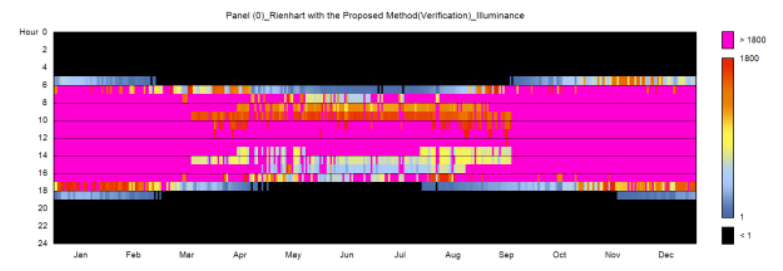

(c)

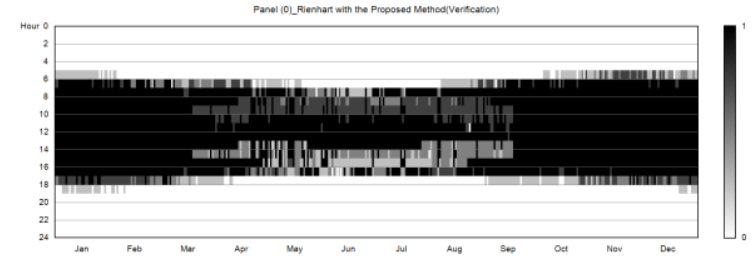

(d)

Figure 8. Further comparison between both approaches using the daylight availability (illuminance values available after blinds are drawn from Figure 7). (a) Proposed methodology - annual vertical illuminance values still available after blinds were drawn from Figure $7 b$. (b) Proposed methodology - annual blind shade use based on the available vertical illuminance from (a). (c) Lightswitch-2002annual horizontal illuminance values still available after blinds were drawn from Figure 7c. (d) Lightswitch-2002 - annual blind shade use based on the available horizontal illuminance from $(c)$.

To further this point, an additional comparison was made between both approaches. In Lightswitch-2002, the horizontal illuminance is automatically calculated from the solar irradiance as part of its output. This was extracted (see Figure 8c) to simulate a subsequent blind schedule shown in Figure 8d. This was also repeated using the proposed methodology as shown in Figure 8a (annual vertical illuminance) and Figure $8 \mathrm{~b}$ (annual blind schedule). This comparison was only made possible since the blind shade was set to the same opacity realistic of solar blind shades $(5 \%)$. The results confirm that blind shade use would be more frequent when simulating the illuminance in Lightswitch-2002. Figure 8c shows the horizontal illuminance levels exceeding $>1800$ that would not have otherwise been detected using the solar 
irradiance (note: illuminance values were based on the daylight availability after blinds were simulated from Figure 7b).

Overall, the results highlighted two important findings. First, illuminance was able to detect more frequent blind use throughout the year compared to solar irradiance. Second, the vertical illuminance was found to be as pertinent as the horizontal illuminance in detecting high illuminance levels and the variation between each glazing panel. Further, in comparison to Lightswitch-2002 the proposed methodology was more flexible in simulating the daylight availability in large open plan offices. DIVA employs a $7 \mathrm{~m}$ horizontal grid depth from the building perimeter with a $1.5 \times 1.5$ sensor radius spacing.

Table 2. Results of the blind schedule simulation for multi-illuminance grid 0 (refer to Figure 3).

\begin{tabular}{|c|c|c|c|c|c|c|c|c|c|c|}
\hline \multicolumn{11}{|c|}{ Multi-illuminance grid 0} \\
\hline & \multicolumn{2}{|c|}{ Sensor 0} & \multicolumn{2}{|c|}{ Sensor 1} & \multicolumn{2}{|c|}{ Sensor 2} & \multicolumn{2}{|c|}{ Sensor 3} & \multicolumn{2}{|c|}{ Sensor 4} \\
\hline Time & $\boldsymbol{E}_{\boldsymbol{h}}$ & $\begin{array}{c}\text { Opening } \\
\%\end{array}$ & $E_{v}$ & $\begin{array}{c}\text { Opening } \\
\%\end{array}$ & $\boldsymbol{E}_{v}$ & $\begin{array}{c}\text { Opening } \\
\%\end{array}$ & $E_{v}$ & $\begin{array}{c}\text { Opening } \\
\%\end{array}$ & $E_{v}$ & $\begin{array}{c}\text { Opening } \\
\%\end{array}$ \\
\hline 24:00:00 & 0 & 0 & 0 & 0 & 0 & 0 & 0 & 0 & 0 & 0 \\
\hline 01:00:00 & 0 & 0 & 0 & 0 & 0 & 0 & 0 & 0 & 0 & 0 \\
\hline 02:00:00 & 0 & 0 & 0 & 0 & 0 & 0 & 0 & 0 & 0 & 0 \\
\hline 03:00:00 & 0 & 0 & 0 & 0 & 0 & 0 & 0 & 0 & 0 & 0 \\
\hline 04:00:00 & 0 & 0 & 0 & 0 & 0 & 0 & 0 & 0 & 0 & 0 \\
\hline 05:00:00 & 68 & 0 & 220 & 25 & 288 & 25 & 104 & 0 & 152 & 0 \\
\hline 06:00:00 & 416 & 25 & 1292 & 75 & 1688 & 75 & 612 & 50 & 896 & 50 \\
\hline 07:00:00 & 832 & 50 & 2584 & 100 & 3328 & 100 & 1204 & 75 & 1792 & 75 \\
\hline 08:00:00 & 1240 & 75 & 3864 & 100 & 4968 & 100 & 1796 & 75 & 2640 & 100 \\
\hline 09:00:00 & 2064 & 100 & 5832 & 100 & 6420 & 100 & 2408 & 100 & 3368 & 100 \\
\hline 10:00:00 & 2112 & 100 & 6292 & 100 & 7220 & 100 & 2632 & 100 & 3872 & 100 \\
\hline 11:00:00 & 1624 & 75 & 5320 & 100 & 7328 & 100 & 2520 & 100 & 4088 & 100 \\
\hline 12:00:00 & 1976 & 100 & 6428 & 100 & 9272 & 100 & 3192 & 100 & 4640 & 100 \\
\hline 13:00:00 & 1536 & 75 & 5076 & 100 & 7296 & 100 & 2504 & 100 & 3932 & 100 \\
\hline 14:00:00 & 1376 & 75 & 4560 & 100 & 6896 & 100 & 2324 & 100 & 3560 & 100 \\
\hline 15:00:00 & 1088 & 50 & 3596 & 100 & 5496 & 100 & 1892 & 100 & 2820 & 100 \\
\hline 16:00:00 & 672 & 50 & 2224 & 100 & 3440 & 100 & 1188 & 50 & 1772 & 75 \\
\hline 17:00:00 & 280 & 25 & 920 & 50 & 1348 & 75 & 472 & 25 & 696 & 50 \\
\hline 18:00:00 & 32 & 0 & 104 & 0 & 136 & 0 & 48 & 0 & 72 & 0 \\
\hline 19:00:00 & 0 & 0 & 0 & 0 & 0 & 0 & 0 & 0 & 0 & 0 \\
\hline 20:00:00 & 0 & 0 & 0 & 0 & 0 & 0 & 0 & 0 & 0 & 0 \\
\hline 21:00:00 & 0 & 0 & 0 & 0 & 0 & 0 & 0 & 0 & 0 & 0 \\
\hline 22:00:00 & 0 & 0 & 0 & 0 & 0 & 0 & 0 & 0 & 0 & 0 \\
\hline 23:00:00 & 0 & 0 & 0 & 0 & 0 & 0 & 0 & 0 & 0 & 0 \\
\hline 24:00:00 & 0 & 0 & 0 & 0 & 0 & 0 & 0 & 0 & 0 & 0 \\
\hline
\end{tabular}

$* E_{h}=$ horizontal illuminance, $E_{v}=$ vertical illuminance and $\%=$ blind opening percentage $(0 \%$ fully opened, $0.25,0.5$ half opened, $0.75,1.0$ fully closed).

Although this might work for smaller offices, it would be hard to adapt this method for large offices, which need a flexible method to configure optimal seating positions for multiple building occupants. This was noted by Reinhart (2004). In addition, one other limitation with DIVA was that it predicted only two states: fully opened $(100 \%)$ and fully closed (0\%). If DIVA was able to read floating values rather than simplifying blind opening percentages, it would be more reflective of occupants occluding a variety of opening percentages (see Table 2). By using this approach, blind shade use can be deterministically predicted by accounting for multiple workstation locations and view-points.

This was achieved by defining the range of the geometrical cones $(5 \mathrm{~m})$ in order to assign and group each sensor point based on its intersection with each glazing panel. If multiple sensors shared the same blind shade, the sensor that read the highest illuminance value would be defined as the most likely occupant to lower the blind shade(s).

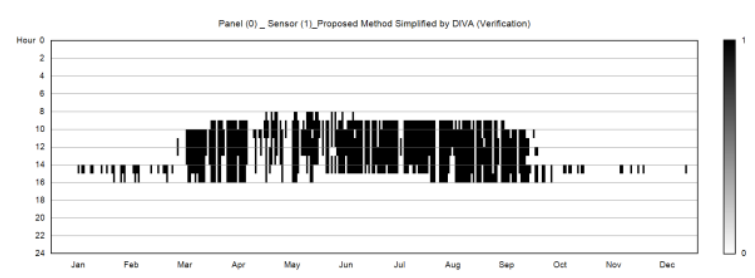

Figure 9. Example of DIVA simplifying annual blind shade use from Figure $8 b$ by using integers.

One limitation to this approach was that it did not consider the adaptive responses which would categorise occupants into active and passive users, as highlighted in literature (Haldi \& Robinson, 2008, 2011). For instance, if one sensor from a datalogger read >1800 lux and a different dataloggers' sensor read between 1200-1800 lux, the active user would be the occupant to occlude the 
blind shade, irrespective of the illuminance value. That is, some occupants are more likely to interact with blind shades than others. The authors are currently conducting field studies to observe the relationship between these variables in real world settings, which will be published in a subsequent paper.

The simulation results can be found in the following link: https://goo.gl/kzUQYJ.

\section{Conclusion}

This paper presented a methodology to simulate annual blind use for large open plan offices. A novel multiilluminance grid was developed to account for multiple occupant workstations and view-points and blind shades. The results showed that by using this method, each blind shade can be simulated to show the opening percentage at an hourly interval across an annual year. In comparison to previous blind use models, this method realistically accounts for the practical implications of collecting empirical data in real-world scenarios, in order to facilitate comparison to field measurements. Further, when comparing this method with existing blind use models, the results found that the illuminance highlighted periods for additional shading. The next stage is to use field results to refine thresholds and validate this approach.

\section{Acknowledgement}

This research was supported by an Australian Research Council (ARC) Linkage Project in joint venture with AECOM. The authors would like to thank Duncan Richards for his continual support and guidance in all aspects of the project.

\section{References}

Asadi, I., Mahyuddin, N., \& Shafigh, P. (2017). A review on indoor environmental quality (IEQ) and energy consumption in building based on occupant behavior. Facilities, 35(11/12), 684-695.

Australian Standards. (2006). Interior and workplace lighting -- Part 1: general principles and recommendations (AS/NZS 1680.1:2006).

Australian Standards. (2008). Interior and workplace lighting -- Part 2.2 Specific applications office screenbased tasks (AZ/NZS 1680.2.2).

Fabi, V., Andersen, R. V., Corgnati, S., \& Olesen, B. W. (2012). Occupants' window opening behaviour: A literature review of factors influencing occupant behaviour and models. Building and Environment, 58, 188-198.

Green Building Council of Australia. (2008). Green star -- office design \& office as built technical manual (GBCA).

Green Building Council of Australia. (2017). Green Star Project Directory. Retrieved from http://www.gbca.org.au/project-directory.asp

Gunay, H. B., O'Brien, W., \& Beausoleil-Morrison, I. (2013). A critical review of observation studies, modeling, and simulation of adaptive occupant behaviors in offices. Building and Environment, 70, 31-47.

Haldi, F., \& Robinson, D. (2008). On the behaviour and adaptation of office occupants. Building and Environment, 43(12), 2163-2177.

Haldi, F., \& Robinson, D. (2010). Adaptive actions on shading devices in response to local visual stimuli. Journal of Building Performance Simulation, 3(2), 135-153.

Haldi, F., \& Robinson, D. (2011). The impact of occupants' behaviour on building energy demand. Journal of Building Performance Simulation, 4(4), 323-338.

Hoes, P., Hensen, J. L. M., Loomans, M. G. L. C., de Vries, B., \& Bourgeois, D. (2009). User behavior in whole building simulation. Energy \& Buildings, 41(3), 295-302.

Inoue, T., Kawase, T., Ibamoto, T., Takakusa, S., \& Matsuo, Y. (1988). The development of an optimal control system for window shading devices based on investigations in office buildings. ASHRAE Transactions, 94, 1034-1049.

Jia, M., \& Srinivasan, R. (2015). Occupant behavior modeling for smart buildings: a critical review of data acquisition technologies and modeling methodologies. WSC '15 Proceedings of the 2015 Winter Simulation Conference, Huntington Beach, California, 06-09 December 2015.

Leadership in Energy and Envrionmental Design. (2013). LEED $v 4$-- reference guide for interior design and construction.

Lindelöf, D., \& Morel, N. (2008). Bayesian estimation of visual discomfort. Building Research \& Information, 36(1), 83-96.

Newsham, G. R. (1994). Manual control of window blinds and electric lighting: implications for comfort and energy consumption. Indoor and Built Environment, 3(3), 135-144.

Reinhart, C. F. (2004). Lightswitch-2002: a model for manual and automated control of electric lighting and blinds. Solar Energy, 77(1), 15-28.

Roche, L., Dewey, E., \& Littlefair, P. (2000). Occupant reactions to daylight in offices. Lighting Research \& Technology, 32(3), 119-126.

Rutten, D. (2014). Grasshopper-Algorithmic modeling for Rhino software version 0.9077. Retrieved from http://www.grasshopper3d.com

Wagdy, A. (2013). New Parametric workflow based on validated day-lighting simulation. Paper presented at the Building Simulation Cairo 2013, Cairo.

Wagdy, A., \& Fathy, F. (2016). A Parametric Approach for Achieving Daylighting Adequacy and Energy Efficiency by Using Solar Screens. Paper presented at the PLEA 2016 - 36th International Conference on Passive and Low Energy Architecture, Los Angeles, California, USA. 